\title{
Validation of the DSP2 Tool in a Contemporary Identified Skeletal Collection from Northeastern Brazil
}

\author{
Salen Marchesi de Almeida1 ${ }^{*}$, Marcus Vitor Diniz de Carvalho', \\ Maria Carolina Tavares de Lyra Menezes' ${ }^{1}$, Gabriela Granja Porto Petraki ${ }^{1}$, \\ Eugénia Cunha², Evelyne Pessoa Soriano ${ }^{1}$ \\ ${ }^{1}$ Center for Studies in Forensic Anthropology (CEAF), University of Pernambuco/UPE, Camaragibe, Brazil \\ ${ }^{2}$ Centre for Functional Ecology, Department of Life Sciences, University of Coimbra, Coimbra, Portugal \\ Email: *salenmarchesi@hotmail.com
}

How to cite this paper: de Almeida, S. M., de Carvalho, M. V. D., de Lyra Menezes, M. C. T., Petraki, G. G. P., Cunha, E., \& Soriano, E. P. (2020). Validation of the DSP2 Tool in a Contemporary Identified Skeletal Collection from Northeastern Brazil. Advances in Anthropology, 10, 169-180.

https://doi.org/10.4236/aa.2020.102010

Received: May 2, 2020

Accepted: May 24, 2020

Published: May 27, 2020

Copyright $\odot 2020$ by author(s) and Scientific Research Publishing Inc. This work is licensed under the Creative Commons Attribution International License (CC BY 4.0).

http://creativecommons.org/licenses/by/4.0/

\begin{abstract}
The Diagnose Sexuelle Probabiliste v.2 (DSP2) is an accurate tool used for estimating the sex of an individual through the os coxae. The goal of this study was to verify the applicability of the DSP2 tool in a skeletal sample from Northeastern Brazil and to attest for its precision, accuracy, and reliability. The sample was composed of 301 os coxae from the Center for Studies in Forensic Anthropology of the College of Odontology from the University of Pernambuco, in Pernambuco, Brazil. The results reveal that it was possible to correctly estimate the sex of $83.7 \%$ of the total sample. The error rate was $0.4 \%$, and the percentage of undetermined individuals varied according to the combination of measurements used. The results demonstrated a high index of accuracy and a low error rate, indicating that DSP2 is a reliable tool for sex estimation applied to this studied Brazilian population.
\end{abstract}

\section{Keywords}

Forensic Anthropology Population Data, Forensic Anthropology, Sex Estimation, Probabilistic Sex Diagnosis, Os Coxae

\section{Introduction}

The biological profile of skeletal remains performed when forensic anthropological analysis is essential for the identification of individuals (Krishan et al., 2016).

The os coxae display their sexual dimorphism pattern throughout the entire 
modern human population, which does not occur with other skeletal elements, such as the cranium, which is population specific. Therefore, the os coxae are a primary choice for studies regarding sex estimation (Brůžek \& Murail, 2006, Murail et al., 2005; Quatrehomme et al., 2017; Brůžek et al., 2017). This generalized display of high sexual dimorphism indicates that the use of population-specific methods and formulas is unnecessary to estimate the sex of an individual when using the os coxae (Murail et al., 2005).

Among the different existing methodologies for sex estimation in the literature, the Diagnose Sexuelle Probabiliste v.2 (DSP2) should be highlighted as an accurate tool, with higher levels of reliability and precision (Brůžek et al., 2017).

Recently, DSP2 was tested in independent populations, including in Brazil. However, considering the continental size of the country and its known racial admixture (Native Brazilians, Europeans, Africans, and Asians) (Oliveiraet al., 2012), it is crucial to validate the tool in different regions of Brazil to cover for its population variation.

The goal of this study was to verify the applicability of the DSP2 on a contemporary identified skeleton collection from Northeastern Brazil, to analyze the precision and reliability of the method as a tool for sex estimation in forensic anthropology to be used in the country.

\section{Materials and Methods}

The sample was composed of 301 human os coxae in a good state of preservation (165 male and 136 female), from adult individuals of known identity, belonging to the Center for Studies in Forensic Anthropology (CEAF) at University of Pernambuco (FOP/UPE), in Pernambuco, Brazil. The CEAF Identified Skeletal Collection is a contemporary collection, with the oldest inhumation dating from the year 2011, and these individuals represent the current population of Northeastern Brazil. The Ethics Committee in Research approved the research at the Pernambuco University (CEP/UPE) under the number 2.284.094, CAAE 72907917.8.0000.5207.

An individual with trauma, pathologies, or morphological anomalies in the os coxae, were excluded from the study. Individuals considered to be non-adults, under 21 years old, with still incomplete development of the skeleton, or with os coxae with a bad state of preservation, which could be brought some prejudice to the measurements, were also excluded.

The age of male individuals varied between 21 - 99 years of age, with a mean age of 60 years old. The age of female individuals varied between $21-109$ years of age, with a mean age of 65 years old. Only the left os coxae were used for the analysis, and they should provide a minimum of 04 variables to be measured.

Two observers, blinded to the sex of the individuals, performed measurements of the ten variables proposed by Murail et al. (2005) and reaffirmed by Brüžek et al. (2017). The number of measurements taken from each os coxae was dependable on the availability of the skeletal structure, with a minimum of four out of ten possible measurements being taken. 
The variables, in descending order of interest, were Acetabulo-symphyseal pubic length (PUM); Cotylo-pubic width (SPU); Innominate or coxal length (DCOX); Greater scieatic notch height (IIMT); Ischium post-acetabular length (ISMM); Iliac or coxal breadth (SCOX); Spino-sciatic length (SS); Spino-auricular length (SA); Cotylo-sciatic breadth (SIS); Vertical acetabular diameter (VEAC) (Murail et al., 2005; Brưžek et al., 2017).

Seven groups of variables (method variation) were tested for the precision of sex estimation. They were: (M1) all the ten variables; (M2) eight variables (DCOS and SCOX were removed); (M3) best combination of four variables (PUM, SPU, DCOS, and IIMT); (M4) four variables from the central parts of the bone, simulating fragmented bone (IIMT, SS, SA, and SIS); (M5) combination of the first nine variables (except VEAC); (M6) combination of the first eight variables (except SIS and VEAC); (M7) worst combination of four variables (SS, SA, SIS, and VEAC).

\section{Statistical Analysis}

Data were analyzed by SPSS 22.0 (IBM ${ }^{\odot}$, Chicago, IL, USA). The Intra Class Correlation Coefficient (ICC) and the confidence interval of $95 \%$ were used to evaluate the inter- and intra-observer replicability. Of the 25 os coxae evaluated, the inter-observation happened between two independent observers, and the intra-observation was done by the same observer within a one-month interval between observations.

The descriptive statistic was performed using measurements of the absolute frequency, percentages, means, standard deviations, and amplitude. The numeric variables were tested for normality through the Shapiro-Wilk test. A Mann-Whitney test was then performed to compare the ten pelvic measurements between males and females. A Chi-square test $\left(\chi^{2}\right)$ was used to compare the frequency of sex estimation (\% of sex estimation) among the seven methods (variables groups). The Chi-square test $\left(\chi^{2}\right)$ and Fisher's exact test were used to compare the most probable sex estimation on inconclusive cases. For all the analyses, the significance was $5 \%$.

\section{Diagnose Sexuelle Probabiliste v2 (DSP 2)}

The Diagnose Sexuelle Probabiliste v2 is a method of sex estimation developed by Murail et al. (2005). It was later improved by the same authors, Brůžek et al. (2017), and it has a global population metric database as a reference, originated from Europe, Africa, North America, and Asia (Murail et al., 2005).

Murail et al. (2005) wanted to validate the hypothesis that the pelvic bones follow a typical sexual dimorphic pattern that is shared among all the modern human population, independent of the geographic region of origin. The authors also had a goal to develop a tool capable of diagnosing the sex and capable of being effectively replicated in different populations.

Therefore, DSP2 contains ten variables groups (anthropological measurements) to estimate sex through the os coxae. Also, one can calculate the sex probability, using any combination of at least four of these proposed variables 
(Murail et al., 2005; Quatrehomme et al., 2017; Brůžek et al., 2017).

Because not every measurement needs to be used to estimate sex through the DSP2 tool, and the possibility of working with a variety of variables combinations, the tool is applicable even when a skeletal element is fragmented (Murail et al., 2005; Quatrehomme et al., 2017; Brưžek et al., 2017). However, the authors clarified that the method's performance is positively correlated to the number of variables used (Murail et al., 2005).

The classic discriminant functional analysis measures the accuracy in classifying the sexes, whereas the DSP2 also provides the reliability of this distinction (Mestekova et al., 2015). Accuracy is understood as the percentage of skeletal remains in which sex is estimated correctly; in the sample, the method is developed. Reliability is evaluated by testing the method in independent populations (Brůžek \& Murail, 2006). Hence, when the confidence level equal or superior to 0.95 is not achieved, the individual is considered as undetermined sex (Murail et al., 2005; Brůžek et al., 2017; Mestekova et al., 2015).

\section{Results and Discussion}

The goal of this study was to validate the DSP2 method in a population sample from Northeastern Brazil to consolidate the tool's use in the practice of forensic anthropology in the country. Currently, independent studies were performed applying DSP2 in European and Brazilian populations.

Chapman et al. (2014) analyzed os coxae derived from the donation program from the University of Brussels (ULB), Mestekova et al. (2015) tested the reliability of the method using CT scan images from a sample of modern French population, and Quatrehomme et al. (2017) studied the os coxae of individuals from the South of France. In Brazil, Machado et al. (2018) validated the method in an osteological collection of a modern population from Southeast Brazil. These studies prove the method's efficiency, and their results are compared to results achieved during the current study.

ICC values varied from 0.926 (IIMT) to 0.996 (SCOX), indicating excellent intra-observer replicability (Table 1 ). For inter-observer replicability, only IIMT (ICC $=0.837)$ showed a value inferior to 0.90 , still demonstrating excellent replicability between independent observers.

The comparative analysis of the ten pelvic measures between females and males is shown in Table 2. SA was the only measure that did not present a statistically significant difference between the sexes $(P=0.0059)$, following the findings of Mestekova et al. (2015). This result is also partially supported by Machado et al. (2018), who did not find statistically significant differences between the sexes with measures SA and PUM.

The measures SPU, DCOX, ISMM, SCOX, SS, SIS and VEAC were higher for males $(P<0.001)$, whereas PUM and IIMT were statistically higher for females $(P<0.001)$, agreeing with the findings by Mestekova et al. (2015) and Quatrehomme et al. (2017). This pattern of bone measures verified in distinct populations 
Table 1. Analysis of intra and inter-observer replicability for the pelvic measurements evaluated in this study.

\begin{tabular}{ccccc}
\hline \multirow{2}{*}{ Variables } & \multicolumn{2}{c}{ Intra-observer } & \multicolumn{1}{c}{ Inter-observer } & \\
\cline { 2 - 5 } & ICC $[95 \% \mathrm{CI}]$ & $\boldsymbol{P}$ & ICC $[95 \% \mathrm{CI}]$ & $\boldsymbol{P}$ \\
\hline PUM & $0.956[0.901-0.980]$ & $<0.001$ & $0.966[0.923-0.985]$ & $<0.001$ \\
SPU & $0.991[0.981-0.996]$ & $<0.001$ & $0.937[0.862-0.972]$ & $<0.001$ \\
DCOX & $0.995[0.990-0.998]$ & $<0.001$ & $0.994[0.986-0.997]$ & $<0.001$ \\
IIMT & $0.926[0.839-0.967]$ & $<0.001$ & $0.837[0.660-0.926]$ & $<0.001$ \\
ISMM & $0.995[0.989-0.998]$ & $<0.001$ & $0.994[0.987-0.997]$ & $<0.001$ \\
SCOX & $0.996[0.991-0.998]$ & $<0.001$ & $0.994[0.986-0.997]$ & $<0.001$ \\
SS & $0.974[0.941-0.988]$ & $<0.001$ & $0.971[0.934-0.987]$ & $<0.001$ \\
SA & $0.994[0.987-0.997]$ & $<0.001$ & $0.983[0.962-0.992]$ & $<0.001$ \\
SIS & $0.973[0.939-0.988]$ & $<0.001$ & $0.988[0.972-0.994]$ & $<0.001$ \\
VEAC & $0.969[0.930-0.986]$ & $<0.001$ & $0.970[0.932-0.986]$ & $<0.001$ \\
\hline
\end{tabular}

ICC $=$ intra class correlation coefficient $\mathrm{CI}=$ confidence interval; $\mathrm{P}=$ significance.

Table 2. Comparative analysis of the ten pelvic measurements among females and males $(\mathrm{n}=301)$.

\begin{tabular}{cccccccc}
\hline \multirow{2}{*}{ Variables } & \multicolumn{3}{c}{ Male } & \multicolumn{3}{c}{ Female } & \multirow{2}{*}{$\boldsymbol{P}$} \\
\cline { 2 - 6 } & Mean & SD & {$[$ Min - Max.] } & Mean & SD & [Min. - Max.] & \\
\hline PUM & 67.83 & 5.01 & {$[56.0-81.6]$} & 70.04 & 4.56 & {$[57.7-80.8]$} & $<0.001$ \\
SPU & 29.84 & 2.54 & {$[23.7-38.1]$} & 24.95 & 2.90 & {$[18.8-34.0]$} & $<0.001$ \\
DCOX & 208.30 & 9.96 & {$[185.3-232.2]$} & 189.38 & 8.94 & {$[169.7-214.7]$} & $<0.001$ \\
IIMT & 36.65 & 4.70 & {$[26.9-48.5]$} & 44.17 & 5.78 & {$[34.1-66.4]$} & $<0.001$ \\
ISMM & 107.74 & 5.62 & {$[104.1-129.3]$} & 95.55 & 4.89 & {$[82.8-106.6]$} & $<0.001$ \\
SCOX & 152.18 & 7.89 & {$[135.2-171.8]$} & 147.00 & 9.15 & {$[119.0-169.8]$} & $<0.001$ \\
SS & 74.59 & 4.98 & {$[63.1-97.0]$} & 67.83 & 4.54 & {$[55.0-83.3]$} & $<0.001$ \\
SA & 75.20 & 6.00 & {$[62.0-97.2]$} & 76.61 & 6.34 & {$[58.9-93.0]$} & 0.059 \\
SIS & 39.61 & 3.59 & {$[32.0-49.9]$} & 35.51 & 3.65 & {$[27.0-48.0]$} & $<0.001$ \\
VEAC & 54.69 & 3.12 & {$[47.6-64.9]$} & 47.80 & 3.42 & {$[33.2-58.9]$} & $<0.001$ \\
\hline
\end{tabular}

$\mathrm{SD}=$ standard deviation; Min.-Max. = minimum-maximum; $P=$ significance $($ Mann-Whitney Test $)$.

corroborates with the idea that os coxae have a characteristic pattern of sexual dimorphism in different geographic regions.

A posterior probability superior to 0.95 was used as a threshold for sex classification. The resulting sex estimation was compared to the known data of each individual. Table 3 presents the results of the 301 skeletons initially analyzed. Sex estimation was possible in $83.7 \%$ of the total sample (male $77.5 \%$ and female 91.2\%). The gross accuracy rate was $83.4 \%$, and the accuracy rate between bones, which had conclusive results was $99.6 \%$, with higher percentages for females 
Table 3. Evaluation of sex estimation via the DSP2 tool $(n=301)$.

\begin{tabular}{cccc}
\hline Variables & Male & Female & Total \\
\cline { 2 - 4 } & & & \\
\hline Sex estimation via DSP2 & 127 & 0 & 127 \\
Male & 1 & 124 & 125 \\
Female & 37 & 12 & 49 \\
Undetermined & 165 & 136 & 301 \\
Total & $77.5 \%(128 / 165)$ & $91.2 \%(124 / 136)$ & $83.7 \%(252 / 301)$ \\
$\%$ sex estimation & $22.5 \%(37 / 165)$ & $8.8 \%(12 / 136)$ & $16.3 \%(49 / 301)$ \\
$\%$ undetermined & $77.0 \%(127 / 165)$ & $91.2 \%(124 / 136)$ & $83.4 \%(251 / 301)$ \\
$\%$ accuracy rate & $99.2 \%(127 / 128)$ & $100 \%(124 / 124)$ & $99.6 \%(251 / 252)$ \\
\% accuracy & &
\end{tabular}

$\%$ sex estimation $=$ frequency of specimens in which sex was estimated. $\%$ undetermined $=$ frequency of samples in which sex estimation could not be performed. \% accuracy rate = frequency of samples in which sex estimation was correct in relation to the total performed. \% accuracy= frequency of samples in which sex estimation was performed correctly from the total of samples possible to be estimated.

(male 99.2\% and female 100\%).

Only one error on sex classification was spotted among the entire sample (classified as female, and which was proven to be morphologically male), resulting in a low error rate $(0.4 \%)$. The result was more satisfactory than the one found by Machado et al. (2018), who had five (9.43\%) pelvic bones misclassified as males and seven (14\%) as females. The high precision rate in this study follows the ones presented by Murail et al. (2005), who showed a precision between $98.7 \%$ to $99.63 \%$ and an error rate of $<2 \%$.

Although 49 os coxae (16.3\%) were not sexed (male $22.5 \%$ and female $8.8 \%$ ), it was possible to verify that female pelvic bones are more accurately classified, an argument that goes against results from Quatrehomme et al. (2017). According to the authors, their study showed that female pelvic bones are more frequently undetermined. However, Chapman et al. (2014) and Machado et al. (2018) had a higher rate of undetermined sex among male bones.

Table 4 shows the results of seven groups of method variations for sex estimation through pelvic measurements. The higher percentages for sex estimation (\% sex estimation) were observed on methods: M5-combination of first nine variables, except VEAC (95.3\%); M6-combination of first eight variables, except SIS and VEAC (94.7\%): M1 - all ten variables (94\%): M2—combination of eight variables, except DCOX and SCOX (92.7\%): and M3-best combination of four variables PUM, SPU, DCOX and IIMT (90.7\%), respectively. The worst results for sex estimation (sex estimation \%) were M7-worst combination of four variables SIS, SA, SS and VEAC (61\%) and M4-four variables from the central parts of the bone (IIMT, SS, SA, and SIS), that simulated fragmented bones (42\%).

The results are compatible with the ones from Brůžek et al. (2017), who 
Table 4. Sex estimation and accuracy through seven variations of the DSP2 method proposed by this study.

\begin{tabular}{ccccc}
\hline Method & Sex estimation & Undetermined & Accuracy rate & Accuracy \\
\hline All ten variables (M1) & & & & \\
Male & $93.7 \%(74 / 79)$ & $6.3 \%(5 / 79)$ & $92.4 \%(73 / 79)$ & $98.6 \%(73 / 74)$ \\
Female & $94.4 \%(67 / 71)$ & $5.6 \%(4 / 71)$ & $94.4 \%(67 / 71)$ & $100 \%(67 / 67)$ \\
Total & $94.0 \%(141 / 150)$ & $6.0 \%(9 / 150)$ & $93.3 \%(140 / 150)$ & $99.3 \%(140 / 141)$ \\
Combination of eight variables, except DCOX and SCOX (M2) & \\
Male & $91.1 \%(72 / 79)$ & $8.9 \%(7 / 79)$ & $89.9 \%(71 / 79)$ & $98.6 \%(71 / 72)$ \\
Female & $94.4 \%(67 / 71)$ & $5.6 \%(4 / 71)$ & $94.4 \%(67 / 71)$ & $100 \%(67 / 67)$ \\
Total & $92.7 \%(139 / 150)$ & $7.3 \%(11 / 150)$ & $92.0 \%(138 / 150)$ & $99.3 \%(138 / 139)$
\end{tabular}

The best combination of four variables-PUM, SPU, DCOX, and IIMT (M3)

$\begin{array}{lcccc}\text { Male } & 92.4 \%(73 / 79) & 7.6 \%(6 / 79) & 92.4 \%(73 / 79) & 100 \%(73 / 73) \\ \text { Female } & 88.7 \%(63 / 71) & 11.3 \%(8 / 71) & 88.7 \%(63 / 71) & 100 \%(63 / 63) \\ \text { Total } & \mathbf{9 0 . 7 \% ( 1 3 6 / 1 5 0 )} & \mathbf{9 . 3 \% ( 1 4 / 1 5 0 )} & \mathbf{9 0 . 7 \% ( 1 3 6 / 1 5 0 )} & \mathbf{1 0 0 \% ( 1 3 6 / 1 3 6 )}\end{array}$

Four variables from the central parts of the bone-IIMT, SS, SA, and SIS (M4)

$\begin{array}{lcccc}\text { Male } & 50.6 \%(40 / 79) & 49.4 \%(39 / 79) & 50.6 \%(40 / 79) & 100 \%(40 / 40) \\ \text { Female } & 32.4 \%(23 / 71) & 67.6 \%(48 / 71) & 30.9 \%(22 / 71) & 95.6 \%(22 / 23) \\ \text { Total } & \mathbf{4 2 . 0 \% ( 6 3 / 1 5 0 )} & \mathbf{5 8 . 0 \% ( 8 7 / 1 5 0 )} & \mathbf{4 1 . 3 \% ( 6 2 / 1 5 0 )} & \mathbf{9 8 . 4 \% ( 6 2 / 6 3 )}\end{array}$

Combination of first nine variables except for VEAC (M5)

$\begin{array}{lcccc}\text { Male } & 94.9 \%(75 / 79) & 5.1 \%(4 / 79) & 93.7 \%(74 / 79) & 98.7 \%(74 / 75) \\ \text { Female } & 95.8 \%(68 / 71) & 4.2 \%(3 / 71) & 95.8 \%(68 / 71) & 100 \%(68 / 68) \\ \text { Total } & 95.3 \%(\mathbf{1 4 3 / 1 5 0 )} & \mathbf{4 . 7 \% ( 7 / 1 5 0 )} & \mathbf{9 4 . 7 \% ( 1 4 2 / 1 5 0 )} & \mathbf{9 9 . 3 \% ( 1 4 2 / 1 4 3 )}\end{array}$

Combination of first eight variables, except SIS and VEAC (M6)

$\begin{array}{lcccc}\text { Male } & 93.7 \%(74 / 79) & 6.3 \%(5 / 79) & 92.4 \%(73 / 79) & 98.6 \%(73 / 74) \\ \text { Female } & 95.8 \%(68 / 71) & 4.2 \%(3 / 71) & 95.8 \%(68 / 71) & 100 \%(68 / 68) \\ \text { Total } & \mathbf{9 4 . 7 \% ( 1 4 2 / 1 5 0 )} & \mathbf{5 . 3 \% ( 8 / 1 5 0 )} & \mathbf{9 4 . 0 \% ( 1 4 1 / 1 5 0 )} & \mathbf{9 9 . 3 \% ( 1 4 1 / 1 4 2 )}\end{array}$

The worst combination of four variables-SIS, SA, SS, and VEAC (M7)

$\begin{array}{ccccc}\text { Male } & 43.5 \%(67 / 154) & 56.5 \%(87 / 154) & 42.9 \%(66 / 154) & 98.5 \%(66 / 67) \\ \text { Female } & 81.2 \%(108 / 133) & 18.8 \%(25 / 133) & 80.4 \%(107 / 133) & 99.0 \%(107 / 108) \\ \text { Total } & 61.0 \%(\mathbf{1 7 5 / 2 8 7}) & \mathbf{3 9 . 0 \% ( 1 1 2 / 2 8 7 )} & \mathbf{6 0 . 3 \% ( 1 7 3 / 2 8 7 )} & \mathbf{9 8 . 9 \% ( 1 7 3 / 1 7 5 )}\end{array}$

$\%$ sex estimation $=$ frequency of specimens in which sex was estimated. $\%$ undetermined $=$ frequency of samples in which sex estimation could not be performed. \% accuracy rate $=$ frequency of samples in which sex estimation was correct in relation to the total performed. \% accuracy = frequency of samples in which sex estimation was performed correctly from the total of samples possible to be estimated.

concluded that using the group of first eight variables, more than $90 \%$ of individuals can be sexed, and by using only the four best variables, more than $87 \%$ of individuals can be sexed. 
Females had the highest percentage of sex estimation for the majority of the methods used, except M3 and M4. The gross accuracy rate (\% accuracy rate) was higher for M5 (94.7\%), M6 (94\%), and M1 (93.3\%). The accuracy rate between bones with conclusive estimation was above $98 \%$ in every other method tested, achieving $100 \%$ when the best combination of four variables was used. This result shows the high level of precision and reliability of DSP2. The comparative analysis of the sex estimation rate and gross accuracy are shown in Figure 1 and Figure 2, respectively.

The undetermined index varied between $4.7 \%$ and $58 \%$, according to the number of variables available. The detailed comparative analysis using ChiSquare is shown in Table 5.

Whenever all ten variables (M1) were used, the undetermined index was $6 \%$.

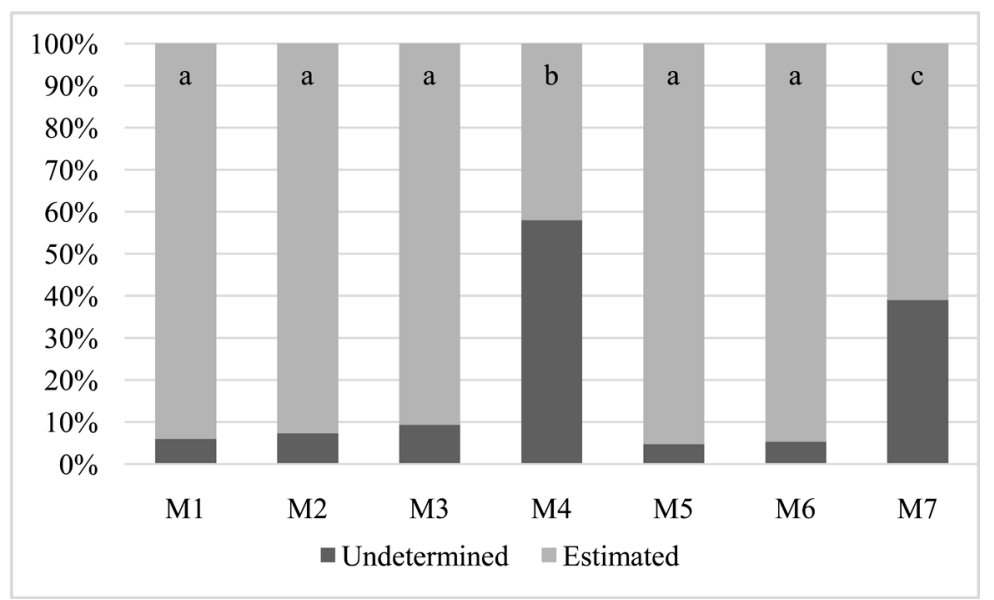

Different lowercase letters show statistically significant differences between methods $(P<0.05$, through Chi-Square).

Figure 1. Comparative analysis of sex estimation rate (\% sex estimation) among seven methods tested.

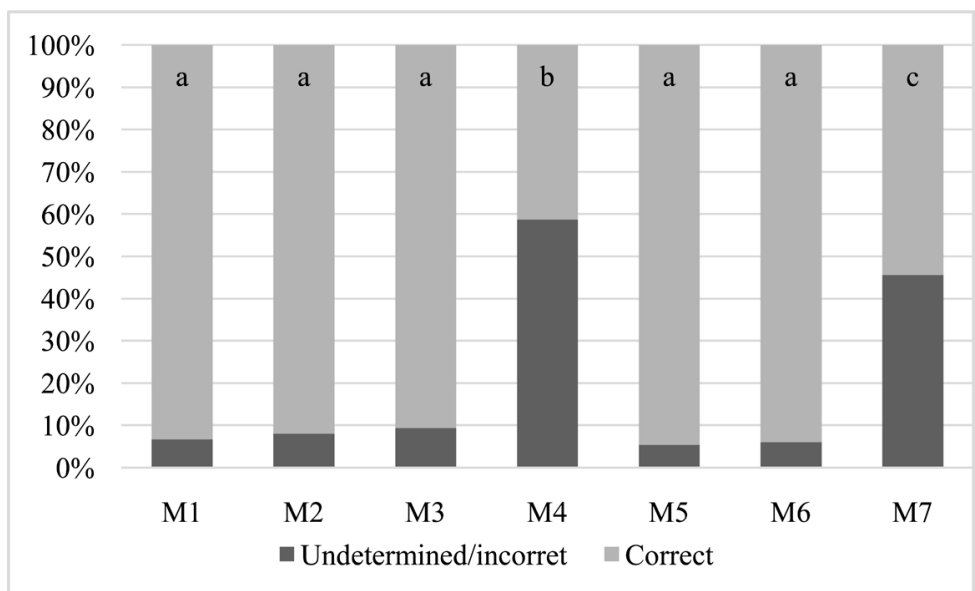

Different lowercase letters show statistically significant differences between methods $(P<0.05$, through Chi-Square).

Figure 2. Comparative analysis of gross accuracy rate (\% accuracy rate) among seven methods tested. 
Table 5. Comparative analysis of sex estimation rate (\% sex estimation) and gross accuracy rate (\% accuracy rate) among seven methods tested.

\begin{tabular}{|c|c|c|c|c|c|c|}
\hline \multirow{2}{*}{ Variables } & M2 & M3 & M4 & M5 & M6 & M7 \\
\hline & \multicolumn{6}{|c|}{$P$} \\
\hline \multicolumn{7}{|c|}{ Sex estimation } \\
\hline M1 & 0.646 & 0.277 & $<0.001$ & 0.610 & 0.806 & $<0.001$ \\
\hline M2 & - & 0.532 & $<0.001$ & 0.329 & 0.475 & $<0.001$ \\
\hline M3 & - & - & $<0.001$ & 0.113 & 0.183 & $<0.001$ \\
\hline M4 & - & - & - & $<0.001$ & $<0.001$ & $<0.001$ \\
\hline M5 & - & - & - & - & 0.791 & $<0.001$ \\
\hline M6 & - & - & - & - & - & $<0.001$ \\
\hline \multicolumn{7}{|c|}{ Accuracy rate } \\
\hline M1 & 0.654 & 0.396 & $<0.001$ & 0.624 & 0.806 & $<0.001$ \\
\hline M2 & - & & $<0.001$ & 0.353 & 0.497 & $<0.001$ \\
\hline M3 & - & - & $<0.001$ & 0.183 & 0.277 & $<0.001$ \\
\hline M4 & - & - & - & $<0.001$ & $<0.001$ & 0.008 \\
\hline M5 & - & - & - & - & 0.806 & $<0.001$ \\
\hline M6 & - & - & - & - & - & $<0.001$ \\
\hline
\end{tabular}

$P=$ Significance (Chi-Square).

According to Chapman et al. (2014), this index was lower, 2.56\%. Quatrehomme et al. (2017) presented 5.17\%, Mestekova et al. (2015) 7.7\% for males and 2.8\% for females, and Machado et al. (2018) registered an index of 14.57\%. If DCOX and SCOX are excluded (M2), the index is $7.3 \%$, being slightly below the result shown by Quatrehomme et al. (2017), 9.37\%.

By using the best combination of four variables (M3), this study shows that 9.3\% of bones were undetermined, considerably lower than the results by Quatrehomme et al. (2017) (23.08\%) and Machado et al. (2018) (17.48\%). For the combination of four variables from the central parts of the bone (M4), the undetermined index reached the highest level among the groups tested, 58\%. Although expressive, the value is lower than the ones reported by Mestekova et al. (2015) (73.1\% males and 63.0\% females) and Quatrehomme et al. (2017) (67.41\%).

When the variable VEAC is excluded (M5), the study reached $4.7 \%$ undetermined index, the lowest among the groups tested. For the group of the first eight variables (M6), the undetermined index was $5.3 \%$, higher than the $2.56 \%$ found by Chapman et al. (2014). The worst combination of four variables (M7) had an undetermined index of 39\%, following findings by Machado et al. (2018) (39.81\%). Therefore, M4 and M7 show percentages statistically higher for undetermined sex estimation than the other groups $(P<0.001)$. Nevertheless, these values were lower, or better, than the ones provided by Quatrehomme et al. (2017), of $47.13 \%$ and $67.41 \%$, respectively. 
These results demonstrate that, as seen in the studies by Mestekova et al. (2015) and Quatrehomme et al. (2017), M7 is not necessarily the worst possible combination of four variables, as M4 presents a higher level of undetermined sex estimation. It is important to note that when the variable VEAC (M5), or SIS and VEAC (M6), are excluded, the undetermined index is lower than when all ten variables are used (M1).

Table 6 shows the comparison of percentages of undetermined pelvic bones among data from the literature and the current study. The analysis presents that the most critical disadvantage of the method is the number of undetermined individuals, depending on the number of variables available. This result happens because of the high threshold for sex classification (0.95), instead of using the usual 0.5. Conversely, the use of such a high threshold reduces the error rate significantly, allowing for better precision and reliability.

The analysis of inconclusive cases is shown in Table 7. The methods M1, M5,

Table 6. Comparison of percentages of undetermined pelvic bones among data from the literature and the current study (M: males; F: females).

\begin{tabular}{|c|c|c|c|c|c|c|}
\hline & Combination of variables & $\begin{array}{c}\text { Chapman } \\
\text { et al. } \\
(n=39)\end{array}$ & $\begin{array}{c}\text { Mestekova } \\
\text { et al. } \\
(n=106) \\
(M ; F)\end{array}$ & $\begin{array}{c}\text { Quatrehomme } \\
\text { et al. } \\
(\mathrm{n}=100) \\
(\mathrm{M} ; \mathrm{F} ; \text { total })\end{array}$ & $\begin{array}{l}\text { Machado } \\
\text { et al. } \\
(\mathrm{n}=103)\end{array}$ & $\begin{array}{l}\text { Current study } \\
\qquad(\mathrm{n}=150) \\
(\mathrm{n}=287)^{\mathrm{a}} \\
(\mathrm{M} ; \mathrm{F} ; \text { total })\end{array}$ \\
\hline M1 & All 10 variables & 2.56 & $7.7 ; 2.8$ & $0.0 ; 5.17 ; 5.17$ & 14.57 & $3.3 ; 2.7 ; 6.0$ \\
\hline M2 & First 8 variables (exceto DCOX e SCOX) & - & $11.5 ; 3.7$ & $1.56 ; 7.81 ; 9.37$ & - & $4.7 ; 2.6 ; 7.3$ \\
\hline M3 & 4 best variables (PUM, SPU, DCOX e IIMT) & 10.26 & $3.8 ; 14.8$ & $1.54 ; 21.88 ; 23.08$ & 17.48 & $4.0 ; 5.3 ; 9.3$ \\
\hline M4 & $\begin{array}{l}4 \text { variables from the central parts of bone } \\
\text { (IIMT, SS, SA, SIS) }\end{array}$ & - & $73.1 ; 63.0$ & $24.72 ; 42.70 ; 67.41$ & - & $26.0 ; 32.0 ; 58.0$ \\
\hline M5 & First 9 variables (except VEAC) & - & - & - & - & $2.7 ; 2.0 ; 4.7$ \\
\hline M6 & First 8 variables (except SIS and VEAC) & 2.56 & - & $0.0 ; 5.08 ; 5.08$ & - & $3.3 ; 2.0 ; 5.3$ \\
\hline M7 & Worst 4 variables (SS, SA, SIS and VEAC) & 46.15 & - & $18.39 ; 28.3 ; 47.13$ & 39.81 & $30.3 ; 8.7 ; 39.0$ \\
\hline
\end{tabular}

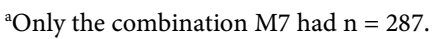

Table 7. Comparative analysis of inconclusive cases on seven methods.

\begin{tabular}{|c|c|c|c|c|c|}
\hline \multirow[t]{2}{*}{ Method } & \multirow[t]{2}{*}{ Total undetermined } & \multicolumn{2}{|c|}{$\begin{array}{c}\text { Probability }>0.5 \\
\text { (Correct sex estimation) }\end{array}$} & \multicolumn{2}{|c|}{$\begin{array}{c}\text { Probability }<0.5 \\
\text { (Incorrect sex estimation) }\end{array}$} \\
\hline & & $\mathrm{n}$ & $\%$ & $\mathrm{n}$ & $\%$ \\
\hline M1 & 9 specimens & 9 & 100 & 0 & 0 \\
\hline M2 & 11 specimens & 10 & 90.9 & 1 & 9.1 \\
\hline M3 & 14 specimens & 10 & 71.4 & 4 & 28.6 \\
\hline M4 & 87 specimens & 71 & 81.6 & 16 & 18.4 \\
\hline M5 & 7 specimens & 7 & 100 & 0 & 0 \\
\hline M6 & 8 specimens & 8 & 100 & 0 & 0 \\
\hline M7 & 112 specimens & 81 & 72.3 & 31 & 27.7 \\
\hline
\end{tabular}

Probability obtained through result from software DSP2. 
Table 8. Results of the Chi-Squared test or Fisher's exact test in comparison to results from inconclusive cases, considering probability higher than 0.5 .

\begin{tabular}{ccccccc}
\hline \multirow{2}{*}{ Method } & M2 & M3 & M4 & M5 & M6 & M7 \\
\cline { 2 - 7 } & & & \multicolumn{5}{c}{$P$} \\
M1 & 1.000 & 0.127 & 0.348 & 1.000 & 1.000 & 0.109 \\
M2 & - & 0.340 & 0.683 & 1.000 & 1.000 & 0.285 \\
M3 & - & - & 0.468 & 0.254 & 0.253 & 1.000 \\
M4 & - & - & - & 0.351 & 0.344 & 0.126 \\
M5 & - & - & - & - & 1.000 & 0.187 \\
M6 & - & - & - & - & - & 0.110 \\
\hline
\end{tabular}

$P=$ Significance (Chi-Square or Fisher's exact test).

M6 obtained $100 \%$ of the correct result in case the DSP2 adopted a probability superior to 0.5. The lowest percentage of correct results was observed for M3 and $\mathrm{M} 7$, which had $71.4 \%$ and $72.3 \%$ of correct classifications, respectively. However, these differences were not statistically significant, as shown in Table 8.

\section{Conclusion}

This study proved that the DSP2 tool has a high replicability rate, and it applies to Brazilian populations. The results showed a high index of accuracy and low error rate, indicating that DSP2 is a reliable tool for sex estimation in forensic anthropology. The best variable combinations (the ones with lower levels of undetermined results) were the first nine or eight (M5 and M6); however, the worst combination was composed of the four variables of the central bone parts (M4). If the level of undetermined cases is considered to be satisfactory when below $10 \%$, every combination can be used, except for M4 and M7. The best combination of four variables (M3), showed a high index of sexual estimation and 100\% accuracy. Thus, they can be used in this Brazilian sample. It was observed that although the tool can be used in fragmented bone, the method should be used with caution when only four variables of the central bone parts are available. Female individuals were more accurately classified. In sum, this study confirms the validity, reliability, and accuracy of the DSP2 tool.

\section{Conflicts of Interest}

The authors declare no conflicts of interest regarding the publication of this paper.

\section{References}

Brůžek, J., \& Murail, P. (2006). Methodology and Reliability of Sex Determination from the Skeleton. In A. Schmitt, E. Cunha, \& J. Pinheiro (Eds.), Forensic Anthropology and Medicine: Complementary Sciences from Recovery to Cause of Death (pp. 225-242). Totowa, NJ: Humana Press Inc.

Brůžek, J., Santos, F., Dutailly, B., Murail, P, \& Cunha, E. (2017). Validation and Reliabil- 
ity of the Sex Estimation of the Human Os Coxae Using Freely Available DSP2 Software for Bioarchaeology and Forensic Anthropology. American Journal of Physical Anthropology, 164, 440-449. https://doi.org/10.1002/ajpa.23282

Chapman, T., Lefevre, P., Semal, P., Moiseev, F., Sholukha V., Louryan, S., Rooze, M., \& Van Sint Jan, S. (2014). Sex Determination Using the Probabilistic Sex Diagnosis (DSP: Diagnose Sexuelle Probabiliste) Tool in a Virtual Environment. Forensic Science International, 234, 189.e1-189.e8. https://doi.org/10.1016/j.forsciint.2013.10.037

Krishan, K., Chatterjee, P. M., Kanchan, T., Kaur, S., Baryah, N., \& Singh, R. (2016). A Review of Sex Estimation Techniques during Examination of Skeletal Remains in Forensic Anthropology Casework. Forensic Science International, 261, 165.e1-165.e8. https://doi.org/10.1016/j.forsciint.2016.02.007

Machado, M. P., Costa, S., Freire, A., Navega, D., Cunha, E., Daruge Junior, E., Prado, F., \& Rossi, A. C. (2018). Application and Validation of Diagnose Sexuelle Probabiliste V2 Tool in a Miscegenated Population. Forensic Science International, 290, 351.e1-351.e5. https://doi.org/10.1016/j.forsciint.2018.06.043

Mestekova, S., Brůžek, J., Valeminska, J., \& Chaumoitre, K. (2015). A Test of the DSP Sexing Method on CT Images from a Modern French Sample. Journal of Forensic Sciences, 60, 1295-1299. https://doi.org/10.1111/1556-4029.12817

Murail, P., Brůžek, J., Houët, F., \& Cunha, E. (2005). DSP: A Tool for Probabilistic Sex Diagnosis Using Worldwide Variability in Hip-Bone Measurements. Bulletins et Mémoires de la Société d'Anthropologie de Paris, 17, 167-176.

Oliveira, O. F., Tinoco, R. L. R., Daruge Júnior, E., Terada, A. S. S. D., Silva, R. H. A., \& Paranhos L. R. (2012). Sexual Dimorphism in Brazilian Human Skulls: Discriminant Function Analysis. Journal of Forensic Odontostomatology, 30, 26-33.

Quatrehomme, G., Radoman, I., Nogueira, L., du Jardin, P., \& Alunni, V. (2017). Sex Determination Using the DSP (Probabilistic Sex Diagnosis) Method on the Coxal Bone: Efficiency of Method According to Number of Available Variables. Forensic Science International, 272, 190-193. https://doi.org/10.1016/j.forsciint.2016.10.020 